This item was submitted to Loughborough's Research Repository by the author.

Items in Figshare are protected by copyright, with all rights reserved, unless otherwise indicated.

\title{
City-level water-energy nexus in Beijing-Tianjin-Hebei region
}

\section{PLEASE CITE THE PUBLISHED VERSION}

https://doi.org/10.1016/j.apenergy.2018.10.097

\section{PUBLISHER}

(c) Elsevier

\section{VERSION}

AM (Accepted Manuscript)

\section{PUBLISHER STATEMENT}

This paper was accepted for publication in the journal Applied Energy and the definitive published version is available at https://doi.org/10.1016/j.apenergy.2018.10.097.

\section{LICENCE}

CC BY-NC-ND 4.0

\section{REPOSITORY RECORD}

Li, Xian, Lili Yang, Heran Zheng, Yuli Shan, Zongyong Zhang, Malin Song, Bofeng Cai, and Dabo Guan. 2019. "City-level Water-energy Nexus in Beijing-tianjin-hebei Region". figshare. https://hdl.handle.net/2134/38362. 


\title{
Accounting of City-level Water-energy Nexus in Beijing-Tianjin-Hebei Region
}

Xian Li ${ }^{1,2}$, Lili Yang ${ }^{1,3}$, Heran Zheng ${ }^{2}$, Yuli Shan ${ }^{4}$, Zongyong Zhang ${ }^{2,5}$, Malin Song ${ }^{6}$, Bofeng Cai ${ }^{7}$, Dabo Guan ${ }^{2,8^{*}}$

1. Department of Mathematics, Southern University of Science and Technology, Shenzhen, 518055, China.

2. Water Security Research Centre, School of International Development, University of East Anglia, Norwich NR4 7TJ, UK.

3. School of Business and Economics, Loughborough University, Leicestershire LE11 3TU, UK.

4. Tyndall Centre for Climate Change Research and School of Environmental Science, University of East Anglia, Norwich NR4 7TJ, UK

5. School of Environmental Science and Engineering, Southern University of Science and Technology, Shenzhen, 518055, China.

6. School of Statistics and Applied Mathematics, Anhui University of Finance and Economics, Bengbu, 233030, China.

7. Centre for Climate and Environmental Policy, Chinese Academy for Environmental Planning, Beijing, 100012, China.

8. Department of Earth System Sciences, Tsinghua University, Beijing 100080, China

\begin{abstract}
Water-energy nexus in a city can either prompt or undermine its development. Yet in China, the relevant research is rarely found. This study accounts the city-level water-energy nexus in BeijingTianjin-Hebei region in 2012 from both production and consumption perspectives, where input-output analysis based on city-level input-output tables are applied to conduct consumption-based accounts. Regarding water for energy, Beijing, Tianjin and Tangshan occupy the largest amounts of water for production in the energy sector, at 203 million tonnes (Mt), $148 \mathrm{Mt}$ and $118 \mathrm{Mt}$, and they also consume most water for energy, at $6690 \mathrm{Mt}, 1328 \mathrm{Mt}$ and $1476 \mathrm{Mt}$. In terms of energy for water, Shijiazhuang and Tianjin have the largest amounts of $\mathrm{CO}_{2}$ emissions for production and consumption respectively, at 28 thousand tonnes (Kt) and $1746 \mathrm{Kt}$. Furthermore, local authorities should prioritise electricity sector as it holds $69 \%$ and $72 \%$ of the total water amounts for production and consumption in the energy sector. Besides, integrated management is crucial for cities with low water and energy efficiency (Baoding and Zhangiiakou), and for large $\mathrm{CO}_{2}$ emitters in Hebei province in order to ensure their water and energy sustainability without stunting their economic growth.
\end{abstract}

\section{Key words}

City-level water-energy nexus, Beijing-Tianjin-Hebei region, Input-output analysis, Sustainability 


\section{Introduction}

Water and energy are inextricably interlinked. Water is required in a series of energy production processes, such as raw materials extraction and processing, electricity production, thermal plant cooling, waste products treatments and energy-generation facilities maintenance. On the other hand, energy plays an essential part in water-related processes such as desalination of brackish water or seawater, pumping from groundwater aquifers, water transfer from water-rich to water-poor regions, water purification and waste water treatment [1]. If the quality, quantity and accessibility of water is declining, the promotion of a diverse supply of reliable, affordable and sustainable energy will be at stake [2]. Conversely, restricted energy capacities limit the ability to produce clean water $[1,3]$.

In the context of environmental changes and globalisation, water-energy nexus affects the majority of countries worldwide, especially those exposed to natural hazards [4]. French highly-water-dependent electric power systems experienced hydropower shortfalls and large-scale shut-down of its nuclear reactors when a severe heat wave hit the country in August 2003 [5]. Similarly, an extreme drought occurred in Texas in 2011, which resulted in the lowest reservoir levels on record, and a tremendous decrease in its power output [6]. China is also one of the countries often attacked by natural disasters, such as typhoon and floods.

Besides, China is facing perilous water crisis, especially in water-scarce northern China [7], [8]. Yet the United Nations (2018) [9] anticipated that middle- and southern China would undergo increasingly harsh water conditions due to climate change and socioeconomic development. China is also the world's largest energy consumer and has huge energy demands to power its rapid industrialisation and urbanisation [10], [11], [12], [13]. Furthermore, regions abundant in energy are mostly located in arid places in China, which exacerbates its water-energy nexus issues. Aiming to achieve synergic management of water and energy, Chinese government added a water-for-coal plan in water policy Three Redlines in 2013 [14].

Unfortunately, China's city-level water-energy nexus is still poorly understood and the issues remain unsolved despite the fact that cities are the basic units for local governments to implement policies as the center for population and human activities, and that how a city obtains, distributes and manages its water and energy supply directly affects its growth [15]. Moreover, relevant studies are rather limited due to the lack of city-level water and energy statistics and of city-level input-output tables. To bridge the gap, we newly compiled city-level water and energy data, and investigated embodied water/energy in the energy/water sector in Chinese cities by applying input-output analysis for the very first time. Regarding research scope, we chose cities in Beijing-Tianjin-Hebei region, including municipalities Beijing and Tianjin along with eleven prefecture cities in Hebei province. The cities could be servicebased (Beijing), high-tech oriented (Tianjin), light-manufacturing (Shijiazhuang) or heavymanufacturing (Tangshan and Zhangjiakou) [16]. In addition to their water/energy endowments and structure, water-energy nexus in these cities can then be mirrored in other Chinese or international cities with similar water/energy patterns and at similar development stages.

\section{Literature review}

\subsection{Water for energy}

When studying water for energy, it is essential to distinguish water withdrawal and water consumption. Water withdrawal quantifies the total removal of water from a source, including water consumption and what is returned to its original watershed [17]. Some literature differentiated from the two concepts [18], while some emphasised one aspect over the other even if they had recognised their difference. Mielke et al (2010) [19] focused on water consumption of energy extraction, processing and conversion. Sovacool and Sovacool (2009) [20] used 'water use' to describe the water withdrawal and consumption together at most points throughout their paper for the sake of simplicity.

Most of the literature have studied water for electricity or power generation in the United States. Averyt et al (2008) [21] compiled a database to calculate water for power plants in the US. Many American researchers conducted life cycle assessments to consolidate water estimates for the full life 
cycle of various electricity generating technologies, including both conventional technologies (coal and natural gas), and renewable technologies (concentrating solar, geothermal, photovoltaics, and wind power) [22], [23], [24], [25]. There is research regarding water for energy on other geographic

levels, but most of them are still associated with electricity generation. Spang et al (2014) [26] posited an indicator-based framework for calculating water for energy production at global level. Van Vliet et al (2016) [3] presented a global assessment of the vulnerability of the world's hydropower and thermoelectric power-generation system to water resources, and tested adaption options for sustainable water-energy security during the $21^{\text {st }}$ century. Byers et al (2014) [27] concentrated on cooling water use in electricity generation in the UK and aimed to design a pathway to less waterintensive energy industry. Murrant et al (2015) [28] estimated the water availability in the UK and analysed the implications on its thermal power generation. Yu et al (2011) [29] evaluated the water loss in China's coal-fired electricity industry. However, some research considered more processes. Rio Carrillo and Frei (2009) [2] analysed water needs for energy production in Spain, concerning several process types, including extraction and refining of raw materials, and thermal plant use.

\subsection{Energy for water}

Various energy processes related to water have been studied. Cohen et al (2004) [30] divided energyfor-water supply-use-disposal chain into five stages which included source and conveyance, treatment, distribution, end use and wastewater treatment. And Copeland and Carter (2017) [31] designated a systematic way to investigate energy for various water source (surface water and groundwater pumping), ways of treatment (treatment of high-ambient quality raw water and of brackish or seawater), intended end-use, means of distribution and amount of water loss in the system through leakage and evaporation, and level of wastewater treatment. Plappally and Lienhard (2012) [32] also added energy use for water reclamation. Rothausen and Conway (2011) [33] argued that not only 'operational' processes, but also 'construction' functions of energy-related water-processes should be considered by involving infrastructure construction and manufacturing of equipment. Yet disagreements exist in terms of which processes should be included. Some researchers held that enduse should not be taken into consideration as a part of energy processes in the water sector.

The existing research covered several aspects in different areas. Sanders and Webber (2012) [34] quantified water-related energy use in the US in order to establish a benchmark for energy-intensive water industry in the country. Liu et al (2016) [35] estimated water-related energy consumption for fourteen global regions, such as Canada, Middle East and China. Racoviceanu et al (2014) [36] analysed life-cycle energy use for water treatment systems in Canada. Li et al (2016) [37] disaggregated and quantified the magnitude and direction of energy and water flows in China through Sankey diagrams to achieve low-energy water utilisation at national level.

\subsection{Water-energy nexus}

Similar to energy for water, many researchers attempted to define 'water-energy nexus' but not yet reached a consensus. Some of them supported Gleick's opinions. Gleick (1994) [1] brought up with the 'water-energy nexus' concept and elaborated water-related energy processes and energy-related water processes. Kyle et al (2016) [38] also proposed that 'water for energy' or 'energy for water' should only refer to water or energy used for processes whose main output is energy or water, and therefore end-use demands and commodities are categorised as 'water and energy for other purposes'. Yet some broadened their research to end-use. Hamiche et al (2016) [39] furthermore categorised the water and energy interdependency into production links, transportation links and consumption links, demonstrating the flow sequence from the environment to the end users.

Research about water-energy nexus could be divided into four main types with regard to their contents. First, they could be theoretical literature discussing water-energy nexus. Retamal et al (2008) [40] provided a detailed literature review from various perspectives, such as water-energy nexus at micro- and macro level. Second, they could be comprehensive reports published by global or local institutions worldwide. The United Nations (2014) [41] and International Energy Agency (2016) [42] draw attention on global water-energy issues. The US Department of Energy (2014) [5] primarily 
analysed the challenges and opportunities of the water-energy nexus in the United States. Third, they could be policy-oriented. Scott et al (2011) [43] demonstrated how water and energy coupled at multiple scales, and mainly uncovered institutional opportunities and impediments to joint decisionmaking in the US. Qin et al (2015) [14] identified co-benefits and trade-off between water and energy policies in China and argued how their coordination can be improved. Fourth, they could be quantitative research.

Several quantitative methods to study water-energy nexus were adopted by previous researchers. Some researchers adopted dynamic computable general equilibrium model. Zhou et al (2016) [44] built a multi-sectoral model to analyse how energy taxes influence water and energy resources. Zhou et al (2018) [45] assessed water-saving co-benefit of long-run energy efficiency improvement. Meanwhile, there are other methods. Zhuang (2014) [46] constructed a system dynamics approach model for integrated water and energy resources management. Yet examining water-energy nexus by using input-output analysis has been the most popular. Okadera et al (2015) [47], Liu et al (2016) [48] and Sun et al (2018) [49] evaluated the water footprint of the energy supply in Liaoning, Hebei and Shaanxi Province in China respectively. And some researchers furthermore developed diverse methods based on input-output analysis. Wang and Chen (2016) [50] conducted ecological network analysis based on the multiregional input-output table in Beijing-Tianjin-Hebei region. Wang et al (2017) [51] proposed a modified input-output model to analyse energy and water flows analysis for urban use. Fang and Chen (2017) [52] combined input-output and linkage analysis to explore the embodied water and energy flows in urban economy in Beijing.

According to geographic scales, the existing literature can be divided into four categories: transboundary-level, national-level, regional-level and city-level [53]. Transboundary-level research occurs in a global setting with illustrations of several case studies, such as international reports. National-level studies involve certain country. Malik (2002) [54] examined the nature of water-energy interactions and the coping strategies to address shortages, uncertainties and unreliability of water and energy in India. Hardy et al (2012) [55] explored the water-energy nexus of Spain and offered calculations for the energy used in the water sector and the water required to run the energy sector. Regional-level research could be a large regional scale, or a regional area within a nation. Siddiqi and Anadon (2011) [56] studied water-energy nexus in the Middle East and North Africa region. Perrone et al (2011) [57] coined the concept 'urban resource islands' to consider the implication of geography on a community's water and energy resource acquisition and use in Tucson, Arizona, United States. Yet city-level water-energy nexus studies are relatively limited. In China, Xie et al (2018) [58] used historical data of water and energy consumption of Wuxi city, a main city in Taihu Lake Basin region in Eastern China, to build a water-energy nexus chart in order to map their dynamic changes in the rapid urbanisation process of the past years. Chen and Chen (2016) [59] synthesised connections between water use and energy consumption, and merged them into urban nexus network in Beijing.

This study bridges the research gaps by applying single-regional input-output analysis to quantify city-level water-energy nexus in China for the first time. We sided with Gleick and Kyle's interpretation towards 'water-energy nexus'. And we investigated water in five individual energy sectors: coal (coal mining and dressing), extraction (petroleum and natural gas extraction), coking (petroleum processing and coking), electricity (production and supply of electric power, steam and hot water) and gas (production and supply of gas); and energy in the water sector (production and supply of water). As regards to indicators, we used water withdrawal for water indicator, and $\mathrm{CO}_{2}$ emissions for energy indicator. Different energy types have their own units, which can all be converted into standard coal (with standard unit). In China, changes of $\mathrm{CO} 2$ emissions and standard coal over time have similar patterns as coal is the largest primary energy source. Thus, $\mathrm{CO} 2$ emissions can indirectly reflect the total energy consumed in China.

\section{Methods and data}

3.1 Study area 
Beijing-Tianjin-Hebei region is situated in North China. The population of thirteen cities within the region are illustrated in figure 1. Chinese government set the target of building it into "the world-class city group as the environmental improvement demonstration region' as it has been facing the most severe environmental problems in China [60], [61]. Thus, studies on this region are of great significance.

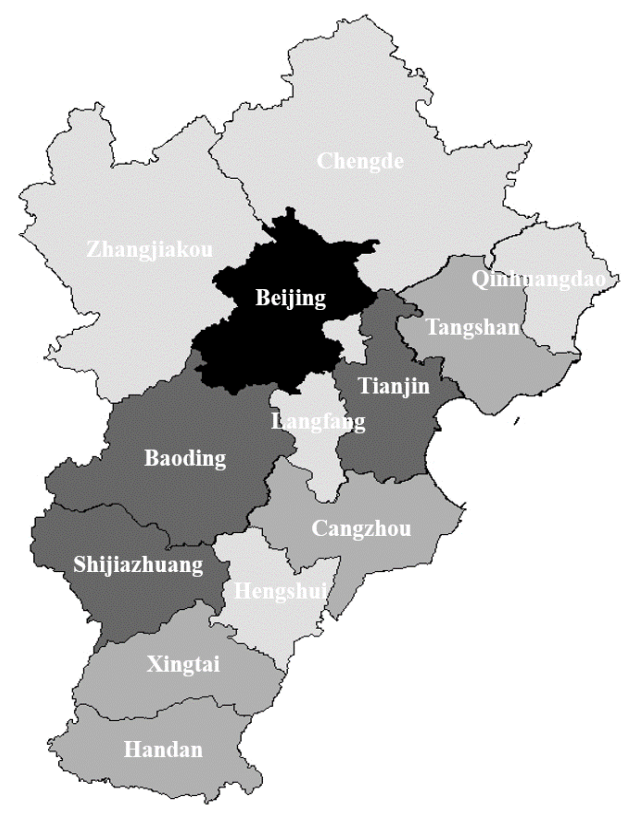

Figure 1 Population of thirteen cities in Beijing-Tianjin-Hebei region in 2012. Beijing (21 million); Tianjin (14 million); Baoding (11 million); Shijiazhuang (10 million); Handan (9 million); Tangshan (8 million); Cangzhou and Xingtai (7 million); Zhangjiakou, Langfang and Hengshui (4 million); Chengde and Qinhuangdao (3 million). Note: The indicator is permanent resident population. All the figures keep no decimal number

The thirteen cities showcase different characteristics of water/energy structure and endowments. Regarding energy, for instance, Tianjin has oil fields (Bohai and Dagang). Tangshan involves a largescale coal mining activities. In addition to petroleum and natural gas, it also develops renewable resources (hydropower, wind/solar power and geothermal energy). As for water, the thirteen cities obtain their water from waterbody, reservoirs and waterworks (surface water and groundwater). Yet water supply of thirteen cities in Beijing-Tianjin-Hebei region are not self-sufficient, so water transfer from other cities/regions are also required.

\subsection{Methods}

Economic input-output analysis was developed by Leontief in the late 1930s, and then extended into environmentally-extended input-output analysis. This study adopts input-output analysis to account production- and consumption-based water/energy. Production-based water/energy is water/energy occurred during domestic production, either for domestic consumption or for exports, while consumption-based water/energy is water/energy embodied in products for domestic consumption, whether it is domestically-produced or imported products.

In this study, matrixes are indicated by bold, upright capital letters; vectors by bold, upright lowercase letters; row vectors, obtained by transposition of the column vectors, by a prime; scalars by italicised letters; and a diagonal matrix by a circumflex. In input-output models, $\mathbf{Z}$ represents intermediate demand matrix with sectors $\mathbf{i}$ and $\mathbf{j} ; \mathbf{y}$ stands for final demand; $\mathbf{e}$ is exports; $\mathbf{m}$ is imports, and $\mathbf{x}$ is total output. In addition, the subscript $\mathrm{d}$ means that the indicators are for domestic production, and the subscript $\mathrm{m}$ represents that the indicators are for imports. 
We first eliminated the effects of intermediary trading by applying the methods validated by Dietzenbacher [62]. Then we separated $\mathbf{Z}_{\mathbf{d}}$ from $\mathbf{Z}, \mathbf{y}_{\mathbf{d}}$ from $\mathbf{y}$ as the city-level input-output tables are competitive, and the proportion of $\mathbf{Z}_{\mathbf{d}}$ in $\mathbf{Z}, \mathbf{y}_{\mathbf{d}}$ in $\mathbf{y}$ can be calculated as:

$$
\alpha_{i}=1-\frac{m_{i}}{\left(x_{i}+m_{i}-e_{i}\right)}
$$

$\mathbf{Z}_{\mathbf{d}}, \mathbf{y}_{\mathbf{d}}$ can then be obtained by multiplying their original matrix or vectors by $\alpha$, demonstrated in equation (1). We then calculated water/energy embodied in domestically-produced products for domestic consumption:

$$
\text { Internal water/energy footprint }=\widehat{\mathbf{f}_{\mathbf{d}}} \mathbf{L}_{\mathbf{d}} \widehat{\mathbf{y}_{\mathbf{d}}}=\widehat{\mathbf{f}_{\mathbf{d}}}\left(\mathbf{I}-\mathbf{A}_{\mathbf{d}}\right)^{-\mathbf{1}} \widehat{\mathbf{y}_{\mathbf{d}}}
$$

We used 2012 national input-output table to calculate the average values of $\mathbf{A}_{\mathbf{m}}$ and $\mathbf{L}_{\mathbf{m}}$ as singleregional input-output analysis cannot tell where a city imports its water/energy [63]. Water/energy embodied in imported products for domestic consumption can be written as:

$$
\text { External water/energy footprint }=\widehat{\mathbf{f}_{\mathbf{m}}} \mathbf{L}_{\mathbf{m}} \widehat{\mathbf{y}_{\mathbf{m}}}=\widehat{\mathbf{f}_{\mathbf{m}}}\left(\mathbf{I}-\mathbf{A}_{\mathbf{m}}\right)^{-\mathbf{1}} \widehat{\mathbf{m}}
$$

In equation (2) and (3), $\mathbf{f}$ is the water/energy intensity, which indicates the water withdrawal/energy consumption each sector contributes in order to produce one unit of its corresponding output. $\mathbf{L}$ is the Leontief inverse matrix, which can also be written as $(\mathbf{I}-\mathbf{A})^{-1}$, whereas $\mathbf{I}$ is a diagonal matrix with 1 on its main diagonal, and $\mathbf{A}$ is $\mathbf{x}^{\prime}$ divided by $\mathbf{Z}$. And $\mathbf{L}$ means the amount of $x$ that sectors in the economic system need to produce to meet $y_{d}$.

\subsection{Data}

$\mathrm{CO}_{2}$ emissions data were compiled by Shan and published in China Emission Accounts and Datasets [64], [65]. Water withdrawal data were also compiled. In Beijing and Tianjin, agricultural water and urban public water (allocated to construction and each service sector) were accessed in the water resources bulletins released by the Horology and Water Resources Investigation Bureaus. And we estimated their water in each industrial sector based on the 2008 water structure in Chinese economic census yearbook assuming the structure remained unchanged in 2012.

In Hebei province's eleven cities, agricultural water was either sourced from the water resources bulletins, or published papers. And we calculated their urban public water with rations between their agricultural water and urban public water. In Tangshan, Qinhuangdao, Zhangjiakou, Chengde and Hengshui, industrial water were collected from their statistic yearbooks. In Shijiazhuang, Handan, Xingtai, Baoding, Cangzhou and Langfang, we assumed that their water intensities in each industrial sector is identical as that in Hebei province. The water intensities $\varepsilon_{\mathrm{j}, \mathrm{k}}=$

$$
\begin{aligned}
& =\frac{\text { industrial water withdrawal }_{j, k}}{\text { industrial output }_{j, k}} \\
& =\frac{{\text { industrial } \text { water }_{\text {withdrawal }}}_{P, k}}{\text { industrial output }_{P, k}}, \mathrm{k} \in[2,27]
\end{aligned}
$$

Here, $\mathrm{j}, \mathrm{p}$ and $\mathrm{k}$ represent cities, Hebei province and industrial sectors respectively. Cities' industrial outputs were accessed in statistic yearbooks, and Hebei province's output was sourced from economic yearbook.

\section{Results and discussions}

\subsection{Water for Energy}

Figure 2 demonstrates water for energy in Beijing-Tianjin-Hebei region. Regarding production-based water for energy, Beijing (203 Mt) and Tianjin (148 Mt) occupy the $1^{\text {st }}$ and the $2^{\text {nd }}$ largest positions, 
followed by Tangshan (118 Mt) and Handan. In contrast, Qinhuangdao (5Mt) has the smallest amount. And water intensities can then be calculated as production-based water divided by total output in each city's energy sector. Baoding, Langfang and Hengshui are the cities with the largest water intensities, while Qinhuangdao has the smallest water intensity, followed by Tianjin and Beijing. In terms of consumption-based water for energy, Beijing (6690 Mt) is the largest, much larger than the second and the third largest city Tangshan (1476 Mt) and Tianjin (1328 Mt). Comparatively, the amount of consumption-based water for energy is rather small in Handan, at 29 Mt. Meanwhile, per capita consumption-based water for energy can also be calculated as consumption-based water divided by population in each city. The per capita consumption-based water is the largest in Beijing at $323 \mathrm{t} /$ person, followed by Tangshan (192 t/person) and Tianjin (94 $\mathrm{t} /$ person). Yet Handan has the least per-capita consumption-based water, at only $3 \mathrm{t} / \mathrm{person}$. It can be observed that the rankings between consumption-based and per capita consumption-based water for energy only have a subtle change, which indicates that population is a main factor that affects water consumption in the energy sector.

Figure 2 also illustrates the thirteen cities' water patterns in five individual energy sectors. As regards production perspective, Tangshan and Handan have the largest amounts of water for coal, at $43 \mathrm{Mt}$ and $39 \mathrm{Mt}$ respectively, while Tianjin only withdraws $10 \mathrm{Kt}$ water for coal. In extraction, Cangzhou, Tangshan and Tianjin occupy the largest amounts of water, at $21 \mathrm{Mt}, 16 \mathrm{Mt}$ and $13 \mathrm{Mt}$ respectively, while Beijing only withdraws $1 \mathrm{Mt}$ water in this sector. In coking, Tianjin, Cangzhou, Tangshan and Beijing have the largest amounts of water, at $30 \mathrm{Mt}, 29 \mathrm{Mt}, 19 \mathrm{Mt}$ and $17 \mathrm{Mt}$. By contrast, Qinhuangdao only has $20 \mathrm{Kt}$ water for coking. As for water for electricity, Beijing (180 Mt) and Tianjin (105 Mt) greatly surpass the others, especially Qinhuangdao (5 Mt), the city with the least water in this sector. In gas, Beijing (2 Mt) is the largest water withdrawer while Zhangjiakou only withdraws $20 \mathrm{Kt}$ water for gas. In respect of consumption perspective, Beijing and Tangshan are ranked as the cities with the largest amounts of water for coal, at $525 \mathrm{Mt}$ and $234 \mathrm{Mt}$, while Langfang only has $3 \mathrm{Mt}$ water for coal. In extraction, Beijing (335 Mt) has the largest amount of water in this sector, followed by Shijiazhuang (122 Mt). Conversely, Hengshui and Chengde have small amounts of water for extraction, only at $1 \mathrm{Mt}$. In coking, the first three largest water consumers are Beijing, Tianjin and Tangshan, at $607 \mathrm{Mt}, 198 \mathrm{Mt}$ and $181 \mathrm{Mt}$ respectively, while the smallest one is Zhangjiakou, which consumes $2 \mathrm{Mt}$ water in this sector. The water for electricity in Beijing (5222 Mt) greatly outweighs the other cities, even the second largest water consumer Tianjin (1053 Mt). Yet Qinhuangdao only has $1 \mathrm{Mt}$ water for electricity. In gas, Shijiazhuang (16 Mt) and Qinhuangdao (10 $\mathrm{Kt}$ ) are the largest and the smallest water consumers respectively. 


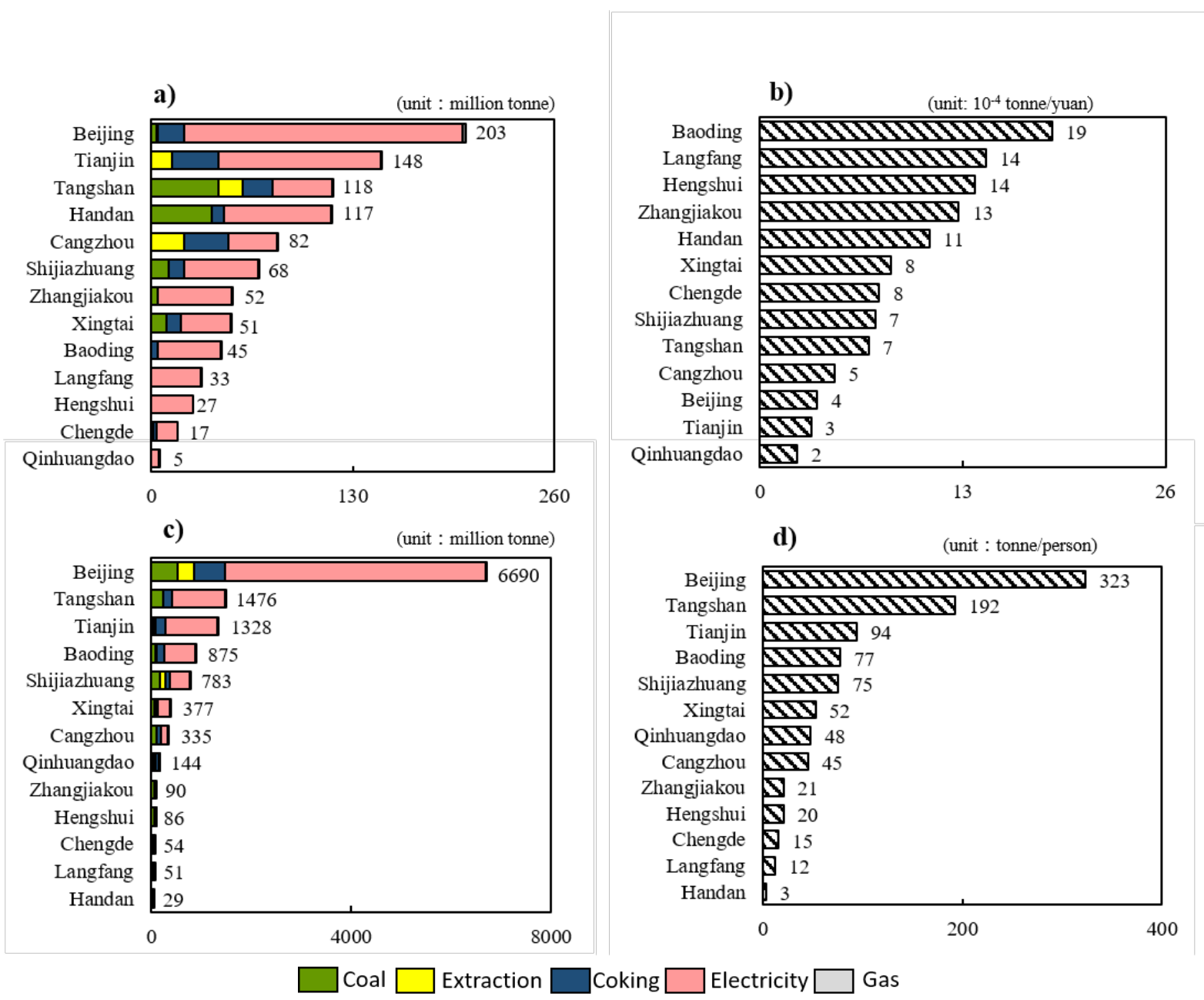

Figure 2 Water for energy. a) production-based water for energy, b) water intensity, c) consumption-based water for energy and d) per capita consumption-based water for energy. Note: All the figures keep no decimal number

Beijing, Tianjin and Tangshan are the largest water withdrawers and consumers in the energy sector. Their consumption-based water are all driven by electricity, and the percentages of water in electricity account for $78 \%, 79 \%$ and $71 \%$ respectively of the total water for energy within the cities. From the production perspective, Beijing and Tianjin still occupy the largest percentages of water in electricity, at $89 \%$ and $71 \%$. Yet Tangshan has $36 \%$, the largest percentage, of its total water withdrawal in coal. Furthermore, it can be observed that electricity contains the largest amounts of water in BeijingTianjin-Hebei region from both production and consumption perspectives. The total amount of production-based water withdrawn in electricity in the thirteen cities takes up 69\% (669 Mt out of 965 $\mathrm{Mt}$ ) of total water withdrawal for energy in the region, and the consumption-based water in electricity accounts for $72 \%$ ( $8857 \mathrm{Mt}$ out of $12318 \mathrm{Mt}$ ) of the total water for energy in the region. Yet based on our calculation, water efficiency in electricity is lower than that in any other energy sector. Therefore, decreasing water amount/improving water efficiency in electricity can dramatically reduce the production-based water/enhance water utilisation in the sector.

\subsection{Energy for Water}

Figure 3 presents energy for water in Beijing-Tian-Hebei region. With regard to production-based energy for water, Shijiazhuang is the largest, at $28 \mathrm{Kt}$, followed by Beijing and Zhangiiakou, at $13 \mathrm{Kt}$ and $7 \mathrm{Kt}$, while the amounts are relatively small in Langfang, Hengshui and Xingtai. Concerning energy intensities, cities with the largest numbers are Shijiazhuang, Baoding and Zhangjiakou. By contrast, Langfang has the smallest energy intensity, followed by Hengshui and Tianjin. As for consumption-based energy for water, Tianjin $(1746 \mathrm{Kt})$ is the largest energy consumer, greatly surpasses Shijiazhuang $(825 \mathrm{Kt})$ and Baoding $(519 \mathrm{Kt})$. In comparison, the amounts of consumption- 
based energy for water are rather small in Qinhuangdao, Langfang and Handan, at $1 \mathrm{Kt}, 8 \mathrm{Kt}$ and 13 $\mathrm{Kt}$ respectively. When per capita consumption-based energy for water is examined, Tianjin, Shijiazhuang and Chengde occupy the first three largest positions. Yet the per-capita consumptionbased energy for water are the smallest in Qinhuangdao, Beijing and Handan.

a)

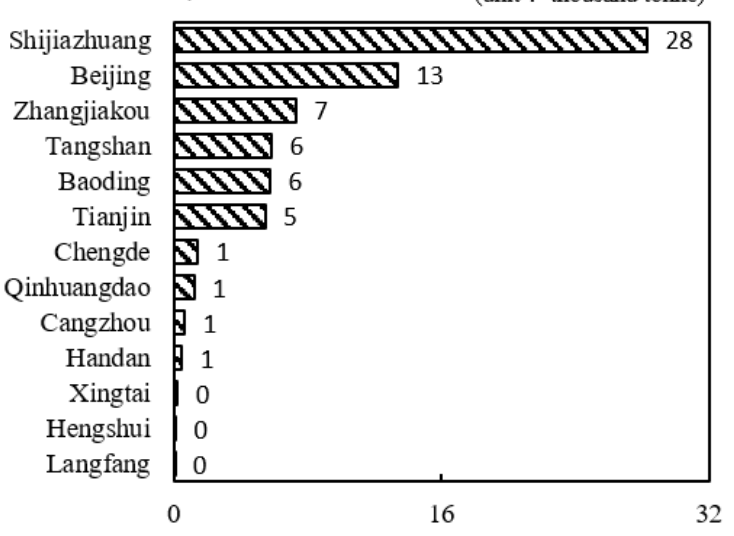

c)

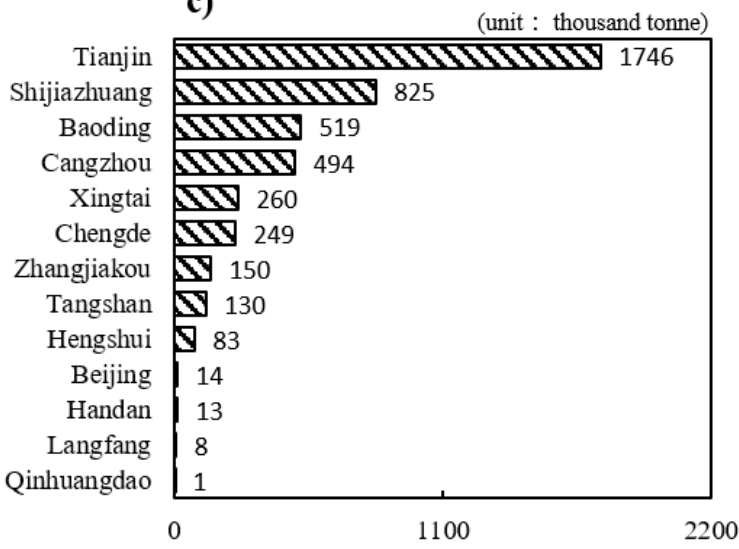

b) (unit : $10^{-7}$ tonne/yuan)

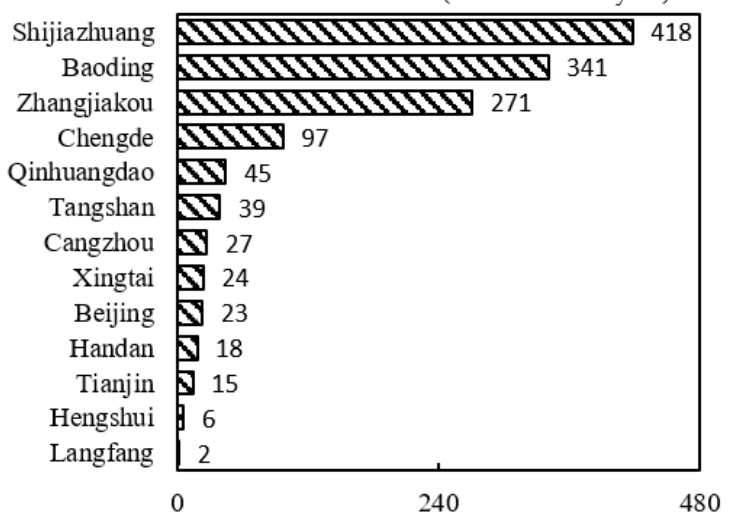

d)

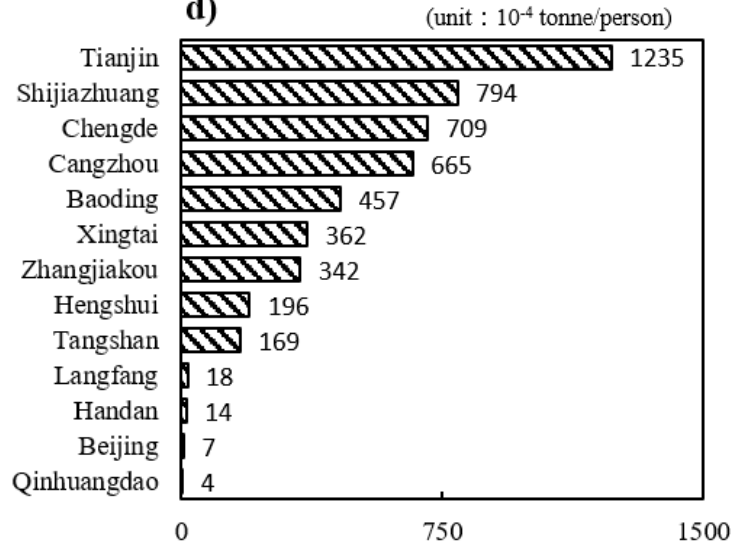

Figure 3 Energy for water. a) production-based energy for water, b) energy intensity, c) consumption-based energy for water, and d) per capita consumption-based energy for water. Note: All the figures keep no decimal number

\subsection{Water-energy nexus}

Figure 4 illustrates the ranking of water/energy intensity versus that of production-based water/energy. The thirteen cities are ranked from large to small numbers/amounts of their intensities/production-based water. Hence, cities with larger water/energy intensities or more production-based water/energy have higher rankings. And water and energy intensities are calculated based on normalising water/energy with total outputs. They refer to the production-based water/energy utilised in the energy/water sector in order to have one unit of corresponding output in the sector, so smaller intensities/lower rankings indicate more efficient water/energy utilisation.

Heterogeneity exists in water-for-energy and energy-for-water patterns. The ranking of water intensity versus production-based water for energy tends to present negative correlation, except for Chengde and Qinhuangdao. The negative correlation suggests that cities with more production-based water in the energy sector tend to have higher water efficiency. Yet Chengde and Qinhuangdao also have efficient water utilisation regardless of their small amounts of water for energy. In contrast, the ranking of energy intensity versus production-based energy for water tends to show positive correlation, with the exception of Beijing and Tianjin. The positive correlation indicates that most large $\mathrm{CO}_{2}$ emitters do not perform efficiently in the water sector. Nevertheless, Beijing and Tianjin 
still remain high efficiency despite their large amounts of $\mathrm{CO}_{2}$ emissions. Thus, strategies of improving efficiency of Hebei province's large $\mathrm{CO}_{2}$ emitters in the water sector need to be executed.

In addition, Baoding has both high water and energy intensities, with its water intensity ranked as the largest $\left(19 \times 10^{-4} \mathrm{t} / \mathrm{CNY}\right)$ and its energy intensity ranked as the $2^{\text {nd }}$ largest $\left(341 \times 10^{-7} \mathrm{t} / \mathrm{CNY}\right)$.

Similarly, Zhangjiakou has its water and energy intensities ranked as the $4^{\text {th }}\left(13 \times 10^{-4} t / C N Y\right)$ and the $3^{\text {rd }}\left(271 \times 10^{-7} \mathrm{t} / \mathrm{CNY}\right)$ largest respectively. In comparison, the water and energy intensities in Beijing and Tianjin are both low. Tianjin has the $2^{\text {nd }}\left(3 \times 10^{-4} \mathrm{t} / \mathrm{CNY}\right)$ and the $3^{\text {th }}\left(15 \times 10^{-7} \mathrm{t} / \mathrm{CNY}\right)$ lowest water and energy intensities respectively. And Beijing's water intensity is the $3^{\text {rd }}$ smallest $\left(4 \times 10^{-4}\right.$ $\mathrm{t} / \mathrm{CNY})$, and its energy intensity is the $5^{\text {th }}$ smallest $\left(23 \times 10^{-7} \mathrm{t} / \mathrm{CNY}\right)$. Technological advancement is a practical and effective means of preventing environmental issues while maintaining economic growth. Cities with low water/energy utilisation in the region need to equip themselves with more advanced facilities and to master more cutting-edge technology and manufacturing techniques. In coking, for instance, brackish and reclaimed water can be recycled to support oil-sand and hydraulic fracturing, which enables less freshwater withdrawal and waste water treatment. In addition, the improvements can be more easily achieved through Beijing-Tianjin-Hebei integration, which drives the synergetic development of all the cities in the region, in aspects of technological exchange, financial support, or justified resource distribution. Besides, the reduction of water/energy for energy/water can also be achieved by replacing traditional resources with renewable or alternative resources.
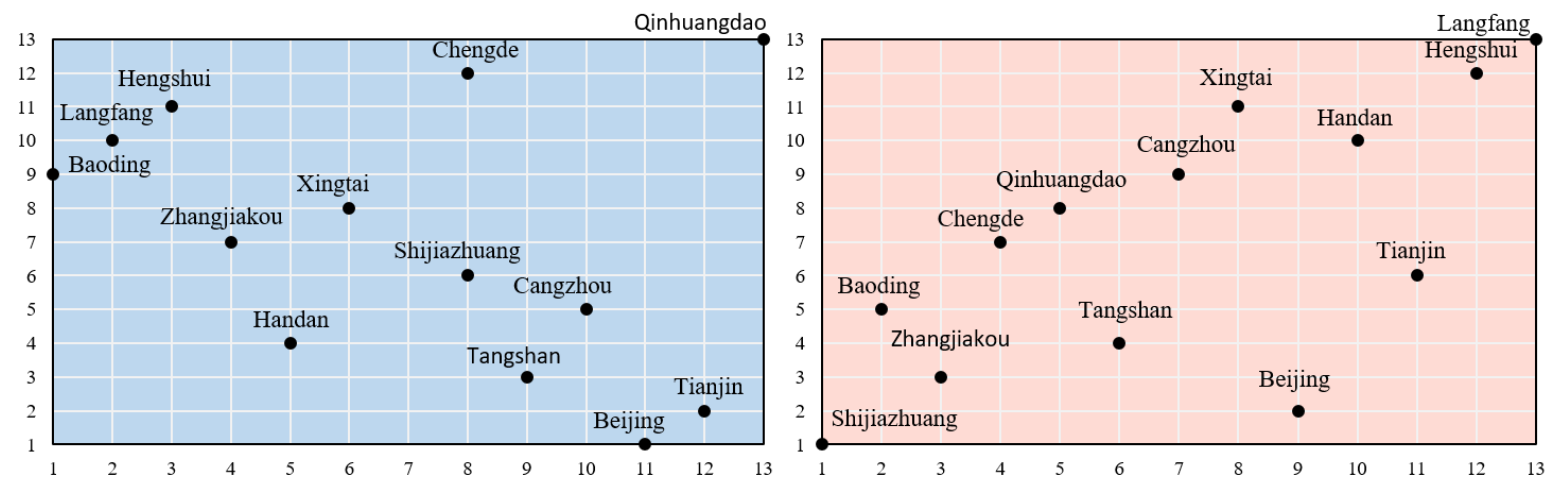

Figure 4 Left (Blue): Ranking: water intensity ( $x$ axis) versus production-based water for energy (y axis). Right (Pink): Ranking: energy intensity ( $x$ axis) versus production-based energy for water ( $y$ axis)

\section{Conclusions}

This study accounts the city-level water-energy nexus in Beijing-Tianjin-Hebei region by applying single-regional input-output analysis from both production and consumption perspectives for the very first time. We clearly elaborated the characteristics of 'water for energy' and 'energy for water' in each city, and then conducted an overall examination of 'water-energy nexus' in the region by combining the two elements.

With regard to water for energy, Beijing, Tianjin and Tangshan are the cities with the largest amounts of water for energy, either from production perspective (203 Mt, $148 \mathrm{Mt}$ and $118 \mathrm{Mt}$ ), or consumption perspective (6690 Mt, $1328 \mathrm{Mt}$ and $1476 \mathrm{Mt}$ ). And the highest water demands are exhibited in electricity among five energy sectors. The production- and consumption-based water in the sector hold $69 \%$ (669 Mt out of $965 \mathrm{Mt})$ and $72 \%$ (8857 Mt out of $12318 \mathrm{Mt}$ ) of water in the entire energy sector in Beijing-Tianjin-Hebei region. Besides, it can be seen that population is a main factor that affects water consumption in the energy sector. Regarding energy for water, Shijiazhuang and Zhangjiakou have the largest amounts of production- and consumption-based $\mathrm{CO}_{2}$ emissions in the water sector, at $29 \mathrm{Kt}$ and $1746 \mathrm{Kt}$ respectively. In water-energy nexus, cities with more water withdrawal in the energy sector tend to have higher water efficiency, while largest $\mathrm{CO}_{2}$ emitters in Hebei province are non-efficient in the water sector. Furthermore, Baoding and Zhangjiakou have both low water/energy utilisation in the energy/water sector. In contrast, Beijing and Tianjin showcase high water/energy efficiency in their energy/water production and supply. Based on our analysis, we suggest that local authorities should strengthen effective management from the following aspects: 1) 
water in electricity (water amounts and water efficiency), 2) the efficiency of large $\mathrm{CO}_{2}$ emitters in Hebei province, and 3) Baoding and Zhangjiakou, cities with both low water and energy utilisation.

Our current study only focuses on city-level water-energy nexus in thirteen cities within BeijingTianjin-Hebei region, but the results can be referred to other domestic and international cities with similar water/energy patterns and at similar developing stages. And our methods of production-based water/energy data compilation and of consumption-based water/energy accounting can also be applied in other areas. However, single-regional input-output analysis itself cannot tell water/energy transfer among cities. In the future, we will adopt other quantitative methods to investigate water-energy nexus with the aim to achieve water and energy sustainability in more cities.

\section{Acknowledgments}

The authors have no conflict of interest to declare.

All the data and results can be download freely from China Emission Accounts and Datasets (CEADs) at http://www.ceads.net.

This work was supported by National Key R\&D Program of China (2018YFC0807000 and 2016YFA0602604), National Natural Science Foundation of China (71771113, 41629501, 71873059, and 71533005), Chinese Academy of Engineering (2017-ZD-15-07), the UK Natural Environment Research Council (NE/N00714X/1 and NE/P019900/1) and the Economic and Social Research Council (ES/L016028/1). 


\section{References}

[1] Gleick PH. Water and energy. Annu. Rev. Energy Environ. 1994; 19: 267-299.

[2] Rio Carrillo AM., Frei C. Water: A key resource in energy production. Energy Policy 2009; 37: 4303-4312.

[3] van Vliet MTH, Wiberg D, Leduc S, Riahi K. Power-generation system vulnerability and adaptation to changes in climate and water resources. Nature Climate Change 2016; 6: 375-381.

[4] Meng J, Mi Z, Guan D, Li J, Tao S, Li Y, Feng K, Liu J, Liu Z, Wang X, Zhang Q, Davis SJ. The rise of South-South trade and its effect on global CO2 emissions. Nature Communications 2018; 9: 1871.

[5] The US. Department of Energy. The water-energy nexus: challenges and opportunities; 2014.

[6] Scanlon BR, Duncan I, Reedy RC. Drought and the water-energy nexus in Texas. Environmental Research Letters 2013: 1-14.

[7] Jiang Y. China's water scarcity. Journal of Environmental Management 2009; 90(11): 3185-3196. King CW, Stillwell AS, Twomey KM, Webber ME. Coherence between water and energy policies. Natural Resources Journal 2013; 53: 117-215.

[8] Seckler D, Barker R, Amarasinghe U. Water scarcity in the twenty-first century. International Journal of Water Resources Development 2010; 15: 29-42.

[9] The United Nations. The United Nations world water development report: nature-based solutions for water. 2018.

[10] Li JS, Zhou HW, Meng J, Yang Q, Chen B, Zhang YY. Carbon emissions and their drivers for a typical urban economy from multiple perspectives: A case analysis for Beijing city. Applied Energy 2018; 226: 1076-1086.

[11] BP Energy Outlook. 2018.

[12] Allan JA. Virtual water: A strategic resource global solutions to regional deficits. Ground Water 1998; 36(4):545-546.

[13] Zheng H, Shan Y, Mi Z, Meng J, Ou J, Schroeder H, Guan D. How modifications of China's energy data affect carbon mitigation targets. Energy Policy 2018; 116: 337-343.

[14] Qin Y, Curmin E, Kopec GM, Allwood JM, Richards KS. China's energy-water nexusassessment of the energy sector's compliance with the "3 Red Lines" industrial water policy. Energy Policy 2015; 82: 131-143.

[15] Li JS, Xia XH, Chen GQ, Alsaedi A, Hayat T. Optimal embodied energy abatement strategy for Beijing economy: Based on a three-scale input-output analysis. Renewable and Sustainable Energy Reviews 2016; 53: 1602-1610.

[16] Shan Y, Guan D, Hubacek K, Zheng B, Davis SJ, Jia L. City-level climate change mitigation in China. Science Advances in Press 2018.

[17] McMahon JE, Price SK. Water and energy interactions. Annu. Rev. Environ. Resour 2011; 36: 163-191.

[18] Williams ED, Simmons JE. Water in the energy industry. An introduction. UK: Pureprint Group Limited; 2013.

[19] Mielke E, Anadon LD, Narayanamurti V. Water consumption of energy resource extraction, processing and conversion. 2010.

[20] Sovacool BK, Sovacool KE. Preventing national electricity-water crisis areas in the United States. 2009.

[21] Averyt K, Macknick J, Rogers J, Madden N, Fisher J, Meldrum J, Newmark R. Water use for electricity in the United States: an analysis of reported and calculated water use information for 2008. Environmental Research Letters 2013; 1-9.

[22] Fthenakis V, Kim HC. Life-cycle uses of water in U.S. electricity generation. Renewable and Sustainable Energy Reviews 2010; 14: 2039-2048.

[23] Grubert EA, Beach FC, Webber ME. Can switching fuels save water? A life cycle quantification of freshwater consumption for Texas coal- and natural gas-fired electricity. Environmental Research Letters 2012; 1-11.

[24] Macknick J, Newmark R, Heath G, Hallett KC. Operational water consumption and withdrawal factors for electricity generating technologies: a review of existing literature. Environmental Research Letters 2012; 1-10. 
[25] Meldrum J, Anderson SN, Heath G, Macknick J. Life cycle water use for electricity generation: a review and harmonization of literature estimates. Environmental Research Letters 2013; 1-18.

[26] Spang ES, Moomaw WR, Gallagher KS, Kirshen PH, Marks DH. Multiple metrics for quantifying the intensity of water consumption of energy production. Environmental Research Letters 2014; 9: 1-8.

[27] Byers EA, Hall JW, Amezaga JM. Electricity generation and cooling water use: UK pathways to 2050. Global Environmental Change 2014; 25: 16-30.

[28] Murrant D, Quinn A, Chapman L. The water-energy nexus: future water resource availability and its implications on UK thermal power generation. Water and Environmental Journal 2015; 29: 307319.

[29] Yu F, Chen J, Sun F, Zeng S, Wang C. Trend of technology innovation in China's coal-fired electricity industry under resource and environmental constraints. Energy Policy 2011; 39: 15861599.

[30] Cohen R, Nelson B, Wolff G. Energy down the drain. The hidden costs of California's water supply. 2004.

[31] Copeland C, Carter NT. Energy-water nexus: the water sector's energy use. 2017.

[32] Plappally AK, Lienhard V JH. Energy requirements for water production, treatment, end use, reclamation, and disposal. Renewable and Sustainable Energy Reviews 2012; 16: 4818-4848.

[33] Rothausen SGSA, Conway D. Greenhouse-gas emissions from energy use in the water sector. Nature Climate Change 2011.

[34] Sanders KT, Webber ME. Evaluating the energy consumed for water use in the United States. Environmental Research Letters 2012; 1-11.

[35] Liu Y, Hejazi M, Kyle P, Kim SH, Davies E, Miralles DG. Global and regional evaluation of energy for water. Environmental Science and Technology 2016; 50: 9736-9745.

[36] Racoviceanu AI, Karney BW, Kennedy CA, Colombo AF. Life-cycle energy use and greenhouse gas emissions inventory for water treatment systems. 2014.

[37] Li X, Liu J, Zheng C, Han G, Hoff H. Energy for water utilisation in China and policy implications for integrated planning. International Journal of Water Resources Development 2016; 32(3): 477-494.

[38] Kyle P, Johnson N, Davies E, Bijl DL, Mouratiadou I, Bevione M. Setting the system boundaries of 'energy for water' for integrated modeling. Environmental Science and Technology 2016; 50: 8930-8931.

[39] Hamiche AM, Stambouli AB, Flazi S. A review of the water-energy nexus. Renewable and Sustainable Energy Reviews 2016; 65: 319-331.

[40] Retamal M, Abeysuriya K, Turner A, White S. Water energy nexus literature review. 2008.

[41] The United Nations. The United Nations World Water Development Report: water and energy. 2014.

[42] International Energy Agency. Water energy nexus. Word Energy Outlook 2016.

[43] Scott CA, Pierce SA, Pasqualetti MJ, Jones AL, Montz BE, Hoover JH. Policy and institutional dimensions of the water-energy nexus. Energy Policy 2011; 39: 6622-6630.

[44] Zhou Y, Li H, Wang K, Bi J. China's energy-water nexus: Spillover effects of energy and water policy. Global Environmental Change 2016; 40: 92-100.

[45] Zhou Y, Ma M, Kong F, Wang K, Bi J. Capturing the co-benefits of energy efficiency in China: A perspective from the water-energy nexus. Resources, Conservation and Recycling 2018; 132, 93101.

[46] Zhuang Y. A system dynamics approach to integrated water and energy resources management. Graduate Theses and Dissertations. 2014.

[47] Okadera T, Geng Y, Fujita T, Dong H, Liu Z, Yoshida N, Kanazawa T. Evaluating the water footprint of the energy supply of Liaoning Province, China: A regional input-output analysis approach. Energy Policy 2015; 78: 148-157.

[48] Liu S, Han M, Wu X, Wu X, Li Z, Xia X, Ji X. Embodied water analysis for Hebei province, China by input-output modelling. Frontiers of Earth Science 2016; 12:72-85.

[49] Sun Y, Shen L, Zhong S, Liu L, Wu N. Water-energy nexus in Shaanxi province of China. Water Science and Technology: Water Supply 2018. 
[50] Wang S, Chen B. Energy-water nexus of urban agglomeration based on multiregional inputoutput tables and ecological network analysis: A case study of the Beijing-Tianjin-Hebei region. Applied Energy 2016; 178: 773-783.

[51] Wang S, Cao T, Chen B. Urban energy-water nexus based on modified input-output analysis. Applied Energy 2017; 196: 208-217.

[52] Fang D, Chen B. Linkage analysis for the water-energy nexus of city. Applied Energy 2017; 189: $770-779$.

[53] Dai J, Wu S, Han G, Weinberg J, Xie X, Wu X, Song X, Jia B, Xue W, Yang Q. Water-energy nexus: A review of methods and tools for macro-assessment. Applied Energy 2018; 210: 393-408.

[54] Malik RPS. Water-energy nexus in resource-poor economies: the Indian experience. International Journal of Water Resources Development 2002; 18(1): 47-58.

[55] Hardy L, Garrido A, Juana L. Evaluation of Spain's water-energy nexus. International Journal of Water Resources Development 2012; 28 (1): 151-170.

[56] Siddiqi A, Anadon LD. The water-energy nexus in Middle East and North Africa. Energy Policy 2011; 39: 4529-4540.

[57] Perrone D, Murphy J, Hornberger GM. Gaining perspective on the water-energy nexus at the community scale. Environmental Science and Technology 2011; 45 (10): 4228-4234.

[58] Xie X, Jia B, Han G, Wu S, Dai J, Weinberg J. A historical data analysis of water-energy nexus in the past 30 years' urbanization of Wuxi city, China. Environmental Progress and Sustainable Energy 2018, 37(1), 46-55.

[59] Chen S, Chen B. Urban energy-water nexus: a network perspective. Applied Energy 2016; 184 : 905-914.

[60] Chen M, Wu S, Lei Y, Li S. Study on embodied $\mathrm{CO}_{2}$ transfer between the Jing-Jin-Ji region and other regions in China: a quantification using an interregional input-output model. Environmental Science and Pollution Research 2018.

[61] Gao Y, Feng Z, Li Y, Li S. Freshwater ecosystem service footprint model: A model to evaluate regional freshwater sustainable development-A case study in Beijing-Tianjin-Hebei, China.

Ecological Indicators 2014; 39: 1-9.

[62] Dietzenbacher E, Los B, Stehrer R, Timmer M, de Vries G. The construction of world inputoutput tables in the WIOD project. Economic Systems Research 2013; 25: 71-98.

[63] Ou J, Meng J, Zheng J, Mi Z, Bian Y, Yu X, Liu J, Guan D. Demand-driven air pollutant emissions for a fast-developing region in China. Applied Energy 2017; 204: 131-142.

[64] Shan Y, Guan D, Liu J, Mi Z, Liu Z, Liu J, Schroeder H, Cai B, Chen Y, Shao S, Zhang Q. Methodology and applications of city level CO2 emission accounts in China. Journal of Cleaner Production 2017; 161: 1215-1225.

[65] Shan Y, Guan D, Zheng H, Ou J, Li Y, Meng J, Mi Z, Liu Z, Zhang Q. China $\mathrm{CO}_{2}$ emission accounts 1997-2015. Scientific Data 2018. 